\title{
Hemodynamic changes in a pregnant patient with congenitally corrected transposition of the great arteries
}

\author{
Carlos Manuel Aboitiz-Rivera1, Ruben Blachman-Braun², Laura Graciela Ferrer-Arellano², \\ Mario Enrique Baltazares-Lipp ${ }^{1}$
}

${ }^{1}$ Servicio de Hemodinamia y Ecocardiografía, Instituto Nacional de Enfermedades Respiratorias (INER), Tlalpan, Distrito Federal, ${ }^{2}$ Facultad de Ciencias de la Salud, Universidad Anáhuac México Norte, Edo. de México, México

\begin{abstract}
Congenitally corrected transposition of the great arteries (CCTGA) is a rare acyanotic heart disease. The evaluation of the hemodynamic alteration, before and after delivery, has been poorly reported. This case report is about a hispanic patient presented in the third trimester of pregnancy with a systolic murmur and a loud second pulmonary sound. Echocardiographic study revealed a CCTGA with dilatation of the morphologically right ventricle (RV), severe regurgitation of the tricuspid valve and secondary pulmonary hypertension without other heart defects. The patient had a full term pregnancy, without any complication before, during or after the childbirth.

Keywords: congenitally corrected transposition of the great arteries, tricuspid valve regurgitation, pulmonary hypertension, echocardiography.
\end{abstract}

\section{Introduction}

Congenitally corrected transposition of the great arteries (CCTGA) is a rare acyanotic heart disease, characterized by a combination of discordant atrioventricular and ventriculoarterial connections. Thus, the morphological right atrium (RA) is connected to the morphological left ventricle (LV) and this last one connected to the pulmonary trunk. Therefore, the morphological left atrium (LA) is connected to the right ventricle (RV) and this one to the aorta which in term means that the RV works as a systemic ventricle [1].

Carl von Rokitansky first described the CCTGA in 1877. The reported incidence is 1 per 33,000 live births, which represent $0.5 \%$ of all congenital heart disease, but

Received 07.06.2014 Accepted 29.07.2014

Med Ultrason

2014, Vol. 16, No 4, 380-382

Corresponding author: Ruben Blachman-Braun

Facultad de Ciencias de la Salud, Universidad

Anáhuac México Norte,

46 Av. Universidad Anahuaca,

Col. Lomas Anáhuac, Huixquilucan,

Edo. de México, C.P. 52786, México

Phone: $+52(55) 56270210$,

Fax: $+52(55) 55961938$

Email: rubenblach@gmail.com in Hispanic population epidemiology remains unknown. The exact etiology of this disease remains unclear. However, some risk factors such as gestational diabetes, maternal use of antiepileptic drugs, environmental pollution and hereditary factors have been associated with this disease. CCGTA can remain asymptomatic for a long period even lifetime and it has been associated with other cardiac defects, including ventricular septal defect, obstruction of the pulmonary outflow tract and lesions of the morphologically tricuspid valve among others $[2,3]$.

\section{Case report}

A 22 year-old hispanic patient in her third trimester of pregnancy, was referred to echocardiography by the gynecology department. Her personal and family history was unremarkable, pregnancy evolution has been normal without any complication. At physical examination, she had tachycardia, auscultation revealed a systolic murmur that was best heard on the fifth left intercostal space, and a loud second pulmonary sound.

Transthoracic echocardiogram was performed and showed a prominent left sided ventricular trabeculation, an infundibulum on the outflow tract, chordae tendinae to the ventricular septum (fig 1), and dilated left sided 
Table I. Hemodynamic status of the patient in the 3rd trimester of pregnancy and four months after delivery.

\begin{tabular}{lcc}
\hline & $\begin{array}{c}\mathbf{3}^{\text {rd }} \text { trimester } \\
\text { of pregnancy }\end{array}$ & $\begin{array}{c}\text { Four months } \\
\text { after delivery }\end{array}$ \\
\hline LV diastolic volume & $60 \mathrm{~mm}^{2}$ & $56 \mathrm{~mm}^{2}$ \\
LV systolic volume & $35 \mathrm{~mm}^{2}$ & $36.7 \mathrm{~mm}^{2}$ \\
Ejection fraction & $71 \%$ & $63 \%$ \\
Pulmonary systolic pressure & $51 \mathrm{mmHg}$ & $28 \mathrm{mmHg}$ \\
Tricuspid valve insufficiency & Severe & Moderate \\
Regurgitate orifice & $0.86 \mathrm{~cm}^{2}$ & $0.226 \mathrm{~cm}^{2}$ \\
Heart rate & $101 \mathrm{bpm}$ & $78 \mathrm{bpm}$ \\
\hline
\end{tabular}

LV- left ventricle

ventricle with a normal ejection fraction, a severe regurgitation of the left sided atrioventricular valve was found ( fig $2 \mathrm{a}$-b). It also revealed a thin trabeculation on the right sided ventricle, absence of moderator band at the apical region and there was no infundibulum at the right sided ventricle (fig 3 ).

We concluded that the patient present discordant atrioventricular and ventriculoarterial connections, because the left sided ventricle was indeed a dilated RV and the right sided ventricle was a LV. Fetal echocardiogram was performed without finding any abnormality. Finally the patient had interpreted as having CCTGA, severe tricuspid regurgitation and secondary pulmonary hypertension, being in Class I of the NYHA classification (Table I). Conservative management was given.

The patient had a full term pregnancy ( $>37$ weeks) without any complication and the baby was born by a cesarean delivery, without any complication or relevant hemodynamic alteration and weighted 2,545 gm. Four months after delivery, a control echocardiography was made and showed improvement of the hemodynamic status tricuspid valve insufficiency and normal pulmonary artery pressure ( fig $2 \mathrm{c}-\mathrm{d}$ ) The patient remains in Functional Class I of the NYHA classification.

\section{Discussions}

The differentiation between RV and LV should be related based on the distinct echocardiographic morphological aspects of the ventricles (table I) [4,5]. In our case the prominent RV trabeculations in the left side give the appearance of a LV noncompaction cardiomyopathy. But, carefully analyzing the characteristics of both ventricles the CCTGA diagnosis was established.

Management of patients with CCTGA involves the treatment of the failing RV and the associated defects and malformations. In some cases the use of diuretics is recommended, also angiotensin converting enzyme in-

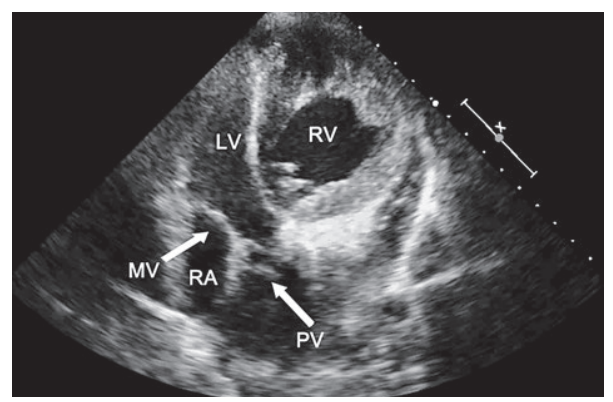

Fig 1. Echocardiographic study: a) mitral valve (MV) and pulmonary valve (PV) continuity in the right sited ventricle (LV) in a modified apical four chambers to assess right outflow tract; b) Septal chordal attachments to the ventricular septum in the left sided ventricle (RV), and apical position of the left tricuspid valve (TV) in apical four chambers view.

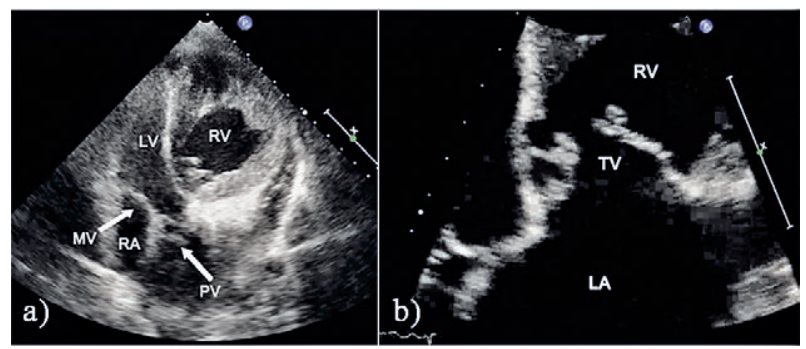

Fig 2. Echocardiographic study during the third trimester of pregnancy ( $a$ and b) and four month after delivery (c and d). a) tricuspid valve (TV) regurgitan orfifice during systole, 3D parasternal short axis; b) severe tricuspid regurgitation, apical four chambers with color Doppler; c) tricuspid valve regurgitan orfifice during systole, parasternal short axis (2D); d) moderate tricuspid regurgitation, apical four chambers with color Doppler.

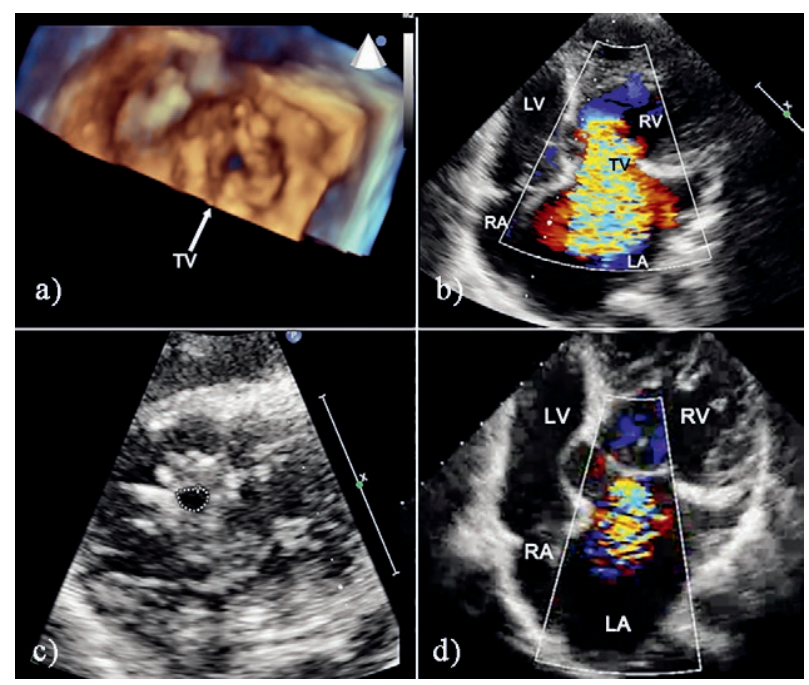

Fig 3. Apical four chambers: discordant atrioventricular and ventriculoarterial connections, where the RA is connected to the $\mathrm{LV}$ and the LA is connected to the RV, coarse trabeculations and the moderated band (MB) can be seen in the RV and the left atrial appendage (LAA) at the LA. 
Tabel II. Echocardiographic characteristics of the right and left ventricles.

\begin{tabular}{|c|c|c|}
\hline & $\begin{array}{c}\text { Right } \\
\text { ventricle }\end{array}$ & $\begin{array}{c}\text { Left } \\
\text { ventricle }\end{array}$ \\
\hline Valve & Tricuspid & Mitral \\
\hline $\begin{array}{l}\text { Tendinous cords attaching to the } \\
\text { ventricular septum }\end{array}$ & Yes & No \\
\hline Moderator band & Yes & No \\
\hline Apical trabeculation & Coarser & Fine \\
\hline Infundibulum at the outflow tract & Yes & No \\
\hline $\begin{array}{l}\text { Continuity between the semilunar } \\
\text { valve and atrioventricular valve }\end{array}$ & No & Yes \\
\hline Semilunar valve position & $\begin{array}{l}\text { Distal to } \\
\text { the apex }\end{array}$ & $\begin{array}{l}\text { Proximal to } \\
\text { the apex }\end{array}$ \\
\hline Shape & Triangular & Conical \\
\hline
\end{tabular}

hibitors and digoxin. When there is a second or third AV block or in the presence of symptoms or ventricular dysfunction, the implantation of a pacemaker is justified. In some patients surgical management should be consider. In this case, the patient did not receive medical treatment after delivery because she was in a Functional Class I of the NYHA classification at the moment of diagnosis. Probably in the future she will need a replacement of the tricuspid valve.

Similar to other published papers [6,7] we observed also that our patient had a successfully full term pregnancy despite of the important hemodynamic alterations induced by the physiological changes during pregnancy. These changes progressed due to volume overload causing dilatation of the $\mathrm{RV}$, dilatation of the atrioventricular fibrous ring, and valve regurgitation. These findings are commonly found in $20 \%-50 \%$ of the patients at the moment of the diagnosis. Pulmonary hypertension can be explained by the volume overload $[3,6-8]$. For these reasons those patients have moderate risk of complications during pregnancy (5-15\%) [9].

During the first trimester of pregnancy the uterus receive $2 \%$ of the cardiac output, the quantity increasing up to $20 \%$ at term. When the pregnancy is over the uterus contracts, therefore hemodynamic changes appear and the circulating volume increases. In patients with cardiac disease this changes could affect the hemodynamic status increasing the risk of complications after delivery. Therefore the patients should be closely observed in a hemodynamic specialized unit [10].

After delivery we found some improvement in patient condition due to the physiological hemodynamic changes that occurred after the end of pregnancy.
The recurrence risk of the CCTGA in the new born babies is $<5 \%$ [3]. For this reason the fetal echocardiography or conventional echocardiography after birth should be performed. In our case, the baby was free of congenital heart disease.

\section{Conclusion}

Women with CCTGA (pregnant or with intentions of getting pregnant) should search for expert medical advice to be appropriately assessed and guided. This case is in our knowledge the first CCTGA reported in Hispanic women in which the volume overload changes induced by pregnancy where assessed before and after delivery. In this particular case the hemodynamic changes had shown important improvement after delivery.

\section{References}

1. Brandão A, Magalhães S, Correia A. Congenitally corrected transposition of the great arteries and aortic coarctation--an uncommon association. Rev Port Cardiol 2004; 23: 993999.

2. Wallis GA, Debich-Spicer D, Anderson RH. Congenitally corrected transposition. Orphanet J Rare Dis 2011; 6: 22.

3. Warnes CA. Transposition of the great arteries. Circulation 2006; 114: 2699-2709.

4. Espinola-Zavaleta N, Soto ME, Castellanos LM, JátivaChávez S, Keirns C. Non-compacted cardiomyopathy: clinical-echocardiographic study. Cardiovase Ultrasound 2006; 4: 35.

5. Ho SY, Nihoyannopoulos P. Anatomy, echocardiography, and normal right ventricular dimensions. Heart 2006; 92(Suppl 1): i2-i13.

6. Connolly HM, Grogan M, Warnes CA. Pregnancy among women with congenitally corrected transposition of great arteries. J Am Coll Cardiol 1999; 33: 1692-1695.

7. Therrien J, Barnes I, Somerville J. Outcome of pregnancy in patients with congenitally corrected transposition of the great arteries. Am J Cardiol 1999; 84: 820-824.

8. Prieto LR, Hordof AJ, Secic M, Rosenbaum MS, Gersony WM. Progressive tricuspid valve disease in patients with congenitally corrected transposition of the great arteries. Circulation 1998; 98: 997-1005.

9. Harris IS. Management of pregnancy in patients with congenital heart disease. Prog Cardiovasc Dis 2011; 53: 305311.

10. Thompson J, Kuklina E, Bateman B, Callaghan W, James A, Grotegut C. Medical and pregnancy complications among women with congenital heart disease at delivery. Am J Obstet Gynecol 2014; 210 (Suppl): S28. 